\title{
Lactosylated Glycogen Nanoparticles for Targeting Prostate Cancer Cells
}

Quinn A. Besford, Marcin Wojnilowicz, Tomoya Suma, Nadja Bertleff-Zieschang, Frank Caruso, ${ }^{*}$ and Francesca Cavalieri*

ARC Centre of Excellence in Convergent Bio-Nano Science and Technology, and the Department of Chemical and Biomolecular Engineering, The University of Melbourne, Parkville, Victoria 3010, Australia

E-mail: fcaruso@unimelb.edu.au; francesca.cavalieri@unimelb.edu.au

${ }^{*}$ To whom correspondence should be addressed 


\begin{abstract}
Glyconanoparticles that exhibit multivalent binding to lectins are highly desirable for molecular recognition and therapeutic applications, for example. Herein, we explore the use of glycogen nanoparticles as a biosourced glyco-scaffold for engineering multivalent glyconanoparticles. Glycogen nanoparticles, a naturally occurring highly-branched polymer of glucose, was functionalized with lactose, achieved through copper(I)-catalyzed alkyne-azide cycloaddition chemistry, for targeted interaction with lectins ex situ and on prostate cancer cells. The lactosylated glycogen, which contains terminal $\beta$-galactoside moieties, is termed galacto-glycogen $(\mathrm{GG})$, and is found to interact strongly with peanut agglutinin (PNA), a $\beta$-galactoside-specific lectin, as observed by optical waveguide lightmode spectroscopy, dynamic light scattering, and quartz crystal microbalance measurements. The GG nanoparticles exhibit multivalent binding to PNA with an affinity constant of $3.4 \times 10^{5} \mathrm{M}^{-1}$, and the GG-PNA complex cannot be displaced by lactose, demonstrating the competitive binding of GG to the lectin. These GG nanoparticles were tested for association with prostate cancer cell membranes in vitro, where the particles exhibited a high affinity for the membrane, as observed from flow cytometry and confocal microscopy. This is inferred to result from specific extracellular galectin-1 targeting. Furthermore, the GG nanoparticles induce aggregation between prostate cancer cells. Our results highlight a strategy for engineering a biosourced polysaccharide with surface moieties that exhibit strong multivalent interactions with lectins, and targeted interaction with prostate cancer cells.
\end{abstract}




\section{Introduction}

The engineering of multivalent glyconanoparticles for efficient targeting of carbohydrate binding proteins in mammalian cells is highly desirable for molecular recognition studies and therapeutic applications. The multivalent receptor-ligand presentation in biological systems is a strategy to compensate for weak and low affinity binding between protein and carbohydrates. ? ? As a result of the multivalency, the overall binding of a multifunctional ligand can be significantly stronger than the combination of the individual binding events of the single

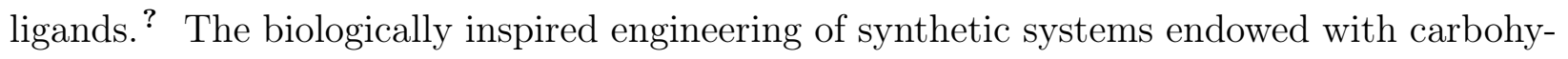
drate ligands in a multivalent form has been extensively pursued in the last decade. ? ? The glyconanoparticles act as a multivalent scaffold carrying multiple copies of carbohydrate ligands, thus increasing the likelihood of binding with the recognition receptors, i.e lectins. Through carbohydrate-lectin interactions, glyconanomaterials can potentially interfere in a wide range of cellular activities, including cell-cell communication, immune response, and bacterial and viral infections. ?

In particular, multivalent carbohydrate binding proteins that mediate malignant cellular activities are intriguing molecular targets. Galectin-1 (Gal-1), for instance, is a homodimeric$\beta$-galactoside binding lectin, which influences tumor progression by modulating interactions between tumor, endothelial, stromal, and immune cells. ${ }^{?}$ Gal-1 is present both inside and outside cells, and has a variety of intracellular and extracellular functions. ${ }^{\text {? }}$ The role of Gal-1 in tumor growth is mediated through the binding of various glycoproteins expressed on a number of different cell types. ' Specifically, Gal-1 has been reported to be involved in multivalent interactions that cluster cell surface glycoproteins, cross-link receptors, and form lattices and larger aggregates. ? ? In human prostate cancer cells, such as PC3 cells, Gal-1 is markedly upregulated during disease progression. ? This highlights the potential of extracellular Gal-1 as a target for drug delivery to inhibit cell proliferation and survival of prostate cancer cells, by using $\beta$-galactoside functionalized-nanoparticles. Galactose residues are also known to be liver-targeting moieties through the organ specificity of the asialoglycoprotein 
receptors.

Synthetic platforms such as glycopeptides, ${ }^{?}$ glycopolymers, ${ }^{?}$ glycodendrimers, ${ }^{?}$ sugarfunctionalized gold, ${ }^{?}$ silica, ${ }^{?}$ iron oxide nanoparticles, ${ }^{?}$ carbon nanotubes, ${ }^{?}$ and liposomes, ${ }^{?}$ with varying valency and spatial organization of multiple carbohydrates, have been used to enhance the affinity of glyco-conjugates towards their receptors. The specific arrangement of the carbohydrate ligands on the surface of nanoparticles, the ligand density, the hydration state of the binding site are, for instance, important elements to tune the binding and targeting properties. In addition, the rational design of glyconanoparticles for in vivo biomedical applications such as targeted drug delivery requires other parameters to be finely engineered. The ideal drug delivery vehicle needs to meet several criteria for successful in vivo interaction with target tissue. These criteria include navigating the serum in such a way so as to avoid loss of functionality post-protein corona formation, ${ }^{?}$ having a long blood circulation lifetime, ${ }^{?}$ the ability to disassemble by cellular internalization stimuli allowing the release of drug cargo, ${ }^{?}$ and finally the degradation products should be non-toxic. ${ }^{?}$ To meet these criteria, a protocol for vehicle synthesis must be devised, and parameters tailored so as to best exploit all possible benefits out of the chosen material.

Hence, the surface and bulk properties of glyconanoparticles, such as hydrophilicity, colloidal stability, toxicity, degradability, immunogenicity, drug loading capacity, must be finely controlled. For instance, the nanoparticles should be highly biocompatible and biodegradable, and the conjugation chemistry used to tether carbohydrates moieties should be carefully designed to prevent nanoparticle aggregation and to avoid unspecific interaction with serum proteins. It is therefore desirable to start with a material that already on its own possesses many desirable qualities, which can then be subtly tuned. Herein, we explore the use of glycogen nanoparticles as a glyco-scaffold for engineering multivalent glyconanoparticles, which have a high affinity for lectins and prostate cancer cells.

Glycogen is a randomly hyperbranched nanoparticle composed of chains of $\alpha$-D-(1-4) glucose units that are interlinked by $\alpha$-D- $(1,6)$ glycosidic linkage to form the branched struc- 
ture. ${ }^{?}$ Glycogen nanoparticles are present in most mammals, ${ }^{?}$ oysters, ${ }^{?}$ sea snails, ${ }^{?}$ and plants, ${ }^{?}$ where they play a vital role in blood glucose homeostasis as well as osmotic pressure regulation. ? ? A number of studies have shown the morphology of glycogen nanoparticles, which are composed of single molecular spheres ( $\beta$-particles) and larger aggregated rosettes of smaller particles ( $\alpha$-particles). Overall, the resulting roughly spherical glycogen particles are about 20-150 $\mathrm{nm}$ in diameter depending on the source, with a polymer-brush-like hydrophilic surface composed of non-reducing ends of glucose.

Glycogen has several distinct advantages as a functional biomaterial, including biocompatibility and biodegradability, availability on a large scale, high water solubility, and ease of functionalization. These properties highlight the potential of glycogen-based nanoparticles as a drug delivery vehicle once functionalized with moieties to target specific receptor proteins. A variety of methods may be used to functionalize glycogen nanoparticles, such as periodate oxidation and reductive amination ${ }^{?}$ to incorporate new amine groups, modification with gadolinium chelating agent for in vivo imaging, ${ }^{?}$ or enzymatic $\alpha$-glucuronylation and subsequent $\alpha$-glucosaminylatin of glycogen to yield $\mathrm{pH}$ responsive hydrogels. ${ }^{?}$ Herein, we use copper(I)-catalyzed alkyne-azide cycloaddition chemistry to functionalize glycogen nanoparticles with lactose moieties that provides terminal $\beta$-galactoside moieties (product termed galacto-glycogen, GG), for the targeted interaction with lectins ex situ and on prostate cancer cells. This is the first example, to our knowledge, of modification of glycogen with other sugar moieties and the synthetic strategy can be applied to other carbohydrates.

We demonstrate a variety of ex situ studies of these functionalized nanoparticles with a $\beta$-galactoside-specific lectin, peanut agglutinin (PNA). We find a strong affinity between GG and PNA, highlighting the potential of GG for targeting Gal-1 in prostate cancer cells. Finally we test this interaction in vitro against prostate cancer cells, which have an overexpression of Gal-1, and find the GG particles successfully target the membrane, which we suggest is due to interaction with extracellular Gal-1 proteins. Our results highlight the potential of using a biosourced and biocompatible nanoparticle as a starting material for 
engineering vehicles for targeted interaction in cancer tissue.

\section{Experimental Section}

\section{Materials}

Bovine liver glycogen (BLG), propargyl bromide, sodium hydride (NaH), copper(II) sulfate hydrate $\left(\mathrm{CuSO}_{4} .5 \mathrm{H}_{2} \mathrm{O}\right)$, sodium ascorbate, D-lactose, boron trifluoride diethyl etherate, sodium methoxide $\left(\mathrm{CH}_{3} \mathrm{ONa}\right)$ solution (25 wt\% in methanol), anhydrous pyridine, anhydrous dimethyl sulfoxide (DMSO), anhydrous methanol (MeOH), anhydrous dimethyl formamide (DMF), acetone, hexane, sodium azide $\left(\mathrm{NaN}_{3}\right)$, tris(3-hydroxypropyl-triazolemethyl) amine, concentrated sulphuric acid, trifluoroacetic acid (TFA), sodium phosphate, sodium chloride $(\mathrm{NaCl})$, calcium chloride $\left(\mathrm{CaCl}_{2}\right)$, magnesium chloride $\left(\mathrm{MgCl}_{2}\right)$, magnesium sulphate, fluorescein isothiocyanate (FITC), phenol, peanut agglutinin (PNA), Concanavalin-A (Con-A), and anhydrous dichloromethane (DCM) were purchased from Sigma Aldrich (MO, USA). Dialysis membrane (10 kDa cut-off) was purchased from Thermo Fisher Scientific (Vic, Australia). PC3 human prostate epithelial cancer cells were obtained from ATCC (collection CRL-1435). DMEM was purchased from Lonza (USA). Fetal bovine serum (FBS) was purchased from Bovogen (Australia). All chemicals were used as received without further purification. High-purity water with a resistivity greater than $18.2 \mathrm{M} \Omega \mathrm{cm}^{-1}$ was obtained from a three-stage Millipore Milli-Q plus 185 purification system (Millipore Corporation, USA).

\section{Galacto-Glycogen}

\section{Synthesis of 1-O-(2-bromoethyl)-hepta- $O$-acetyl- $\beta$-lactoside}

Lactose (7.89 g, $22 \mathrm{mmol})$ was suspended in anhydrous pyridine $(30 \mathrm{~mL})$ and acetic anhydride $(40 \mathrm{~mL})$ under stirring overnight at $23{ }^{\circ} \mathrm{C}$. After $12 \mathrm{~h}$, pyridine was evaporated under 
reduced pressure, then ethyl acetate added $(200 \mathrm{~mL})$. The reaction mixture was then washed with water $(\times 3)$, dilute copper sulphate solution $(\times 3)$, and brine $(\times 3)$, then dried over magnesium sulphate, crystallized in ethanol, and recrystallized from hot ethanol, then dried under high vacuum to obtain peracetylated lactose $(6.5 \mathrm{~g}, 14.3 \mathrm{mmol})$. The dried product $(6.5 \mathrm{~g}, 14.3 \mathrm{mmol})$ was dissolved in anhydrous dichloromethane $(15 \mathrm{~mL})$ with stirring. To this, 2-bromoethanol $(5 \mathrm{~mL}, 71 \mathrm{mmol})$ was added, and the vessel was put on ice under a flux of argon. Boron trifluoride diethyl etherate $(8 \mathrm{~mL}, 65 \mathrm{mmol})$ was added dropwise over $40 \mathrm{~min}$. System was left stirring under an atmosphere of argon at $23{ }^{\circ} \mathrm{C}$ for three days. The reaction was quenched by the addition of saturated sodium bicarbonate, and then washed twice with saturated sodium bicarbonate $(\times 2)$, then water $(\times 3)$, and brine $(\times 3)$. The crude product was collected with ethyl acetate and then concentrated by evaporation. The product was purified by silica gel chromatography (silica gel 60, eluent 1:4 $\rightarrow$ 1:2 acetone:hexane). After drying under reduced pressure, the product (1.53 g, 16\%) was obtained as a pale yellow oil. ${ }^{1} \mathrm{H}-\mathrm{NMR}\left(400 \mathrm{MHz}, \mathrm{CDCl}_{3}\right): 5.35(\mathrm{~d}, \mathrm{~J}=3.3 \mathrm{~Hz}, 1 \mathrm{H}), 5.21(\mathrm{dd}, \mathrm{J}=9.3 \mathrm{~Hz}, 1 \mathrm{H}), 5.11$ $(\mathrm{dd}, \mathrm{J}=7.9$ and $10.4 \mathrm{~Hz}, 1 \mathrm{H}), 4.98-4.89(\mathrm{~m}, 2 \mathrm{H}), 4.56-4.46(\mathrm{~m}, 3 \mathrm{H}), 4.16-4.04(\mathrm{~m}, 4 \mathrm{H}), 3.88$ $(\mathrm{dd}, \mathrm{J}=6.9 \mathrm{~Hz}, 1 \mathrm{H}), 3.84-3.76(\mathrm{~m}, 2 \mathrm{H}), 3.64-3.58(\mathrm{~m}, 1 \mathrm{H}), 3.52-3.40(\mathrm{~m}, 2 \mathrm{H}), 2.15(\mathrm{~s}, 3 \mathrm{H})$, $2.13(\mathrm{~s}, 3 \mathrm{H}), 2.06(\mathrm{~s}, 6 \mathrm{H}), 2.04(\mathrm{~s}, 6 \mathrm{H}), 1.96(\mathrm{~s}, 3 \mathrm{H})$.

\section{Synthesis of 1-O-(2-azidoethyl)-hepta- $O$-acetyl- $\beta$-lactoside}

1-O-(2-Bromoethyl)-hepta- $O$-acetyl- $\beta$-lactoside $(1.53 \mathrm{~g}, 3.4 \mathrm{mmol})$ was dissolved in DMF (10 $\mathrm{mL}), \mathrm{NaN}_{3}(1.38 \mathrm{~g}, 34 \mathrm{mmol})$ added, and left stirring for $16 \mathrm{~h}$ at $23{ }^{\circ} \mathrm{C}$. The product was collected in ethyl acetate and washed with water $(\times 3)$, brine $(\times 3)$, and then concentrated under reduced pressure. The product $(1.21 \mathrm{~g}, 86 \%)$ was obtained as colorless crystals. ${ }^{1} \mathrm{H}-$ NMR $\left(400 \mathrm{MHz}, \mathrm{CDCl}_{3}\right): 5.35(\mathrm{~d}, \mathrm{~J}=3.2 \mathrm{~Hz}, 1 \mathrm{H}), 5.20(\mathrm{dd}, \mathrm{J}=9.2 \mathrm{~Hz}, 1 \mathrm{H}), 5.10(\mathrm{dd}$, $\mathrm{J}=7.9$ and $10.4 \mathrm{~Hz}, 1 \mathrm{H}), 4.98-4.90(\mathrm{~m}, 2 \mathrm{H}), 4.57(\mathrm{~d}, \mathrm{~J}=7.9 \mathrm{~Hz}, 1 \mathrm{H}), 4.52-4.46(\mathrm{~m}, 2 \mathrm{H})$, 4.16-4.05 (m, 3H), 4.02-3.96 (m, 1H), $3.87(\mathrm{dd}, \mathrm{J}=6.6 \mathrm{~Hz}, 1 \mathrm{H}), 3.82(\mathrm{dd}, \mathrm{J}=9.5 \mathrm{~Hz}, 1 \mathrm{H})$, 3.71-3.66 (m, 1H), 3.65-3.59 (m, 1H), 3.51-3.44 (m, 1H), 3.30-3.24 (m, 1H), $2.15(\mathrm{~s}, 3 \mathrm{H}), 2.12$ 
$(\mathrm{s}, 3 \mathrm{H}), 2.06(\mathrm{~s}, 6 \mathrm{H}), 2.04(\mathrm{~s}, 6 \mathrm{H}), 1.96(\mathrm{~s}, 3 \mathrm{H})$.

\section{Synthesis of glycogen alkyne}

BLG (70 mg, $0.43 \mathrm{mmol}$ of glucose) was dissolved in $6 \mathrm{~mL}$ of anhydrous DMSO/DMF (1:2), under an atmosphere of argon. To this, $\mathrm{NaH}(26 \mathrm{mg}, 1.08 \mathrm{mmol})$ was carefully added. The solution was allowed to settle for $10 \mathrm{~min}$, and then taken off ice and allowed to warm to $23{ }^{\circ} \mathrm{C}$. To this, propargyl bromide (20 $\mu \mathrm{L}$ of an 80 wt.\% solution in toluene) was added dropwise over $5 \mathrm{~min}$. The system was allowed to react for $12 \mathrm{~h}$ under an atmosphere of argon. Product was precipitated in cold ethanol, isolated by centrifugation (3000 $\mathrm{g}, 5 \mathrm{~min})$, then washed a further two times with ethanol, and then dispersed in Milli-Q water and freeze-dried overnight. Yield $50.0 \mathrm{mg}(71 \%) .{ }^{1} \mathrm{H}-\mathrm{NMR}\left(400 \mathrm{MHz}, \mathrm{D}_{2} \mathrm{O}\right): 6.16(\mathrm{~s}, 0.11 \mathrm{H})$, $5.92(\mathrm{~s}, 1 \mathrm{H}), 5.52(\mathrm{~s}, 0.16 \mathrm{H}), 5.00(\mathrm{~s}, 0.1 \mathrm{H}), 4.60-4.06(\mathrm{~m}, 9 \mathrm{H}), 4.03-3.93(\mathrm{~m}, 0.35 \mathrm{H}), 3.25(\mathrm{~s}$, $0.05 \mathrm{H})$.

\section{Copper(I)-catalyzed alkyne-azide cycloaddition of lactose azide to glycogen alkyne}

Glycogen alkyne $(50 \mathrm{mg})$ was dissolved in DMSO $(3 \mathrm{~mL})$ and degassed by bubbling argon through the solution. 1-O-(2-Azidoethyl)-hepta- $O$-acetyl- $\beta$-lactoside $(108 \mathrm{mg}, 0.15 \mathrm{mmol})$ was added to this solution. To this mixture, a solution of copper (II) sulfate hydrate, sodium ascorbate, and tris(3-hydroxypropyl-triazole methyl)amine dissolved in minimal degassed Milli-Q (1:1:1) was added to have a final concentration of $1 \mathrm{mM}$. Reaction was protected from light under an atmosphere of argon, and allowed to react overnight. After $12 \mathrm{~h}$, product was isolated by precipitation in cold ethanol followed by centrifugation (3000 $\mathrm{g}, 5 \mathrm{~min})$. The resulting pellet was washed twice with anhydrous methanol, then re-suspended in $5 \mathrm{~mL}$ of anhydrous methanol. Sodium methoxide $(1 \mathrm{~mL})$ was added to this mixture, and the solution was gently agitated for $15 \mathrm{~min}$. The product was then isolated by centrifugation, re-dispersed in 5mL of Milli-Q water, dialyzed against Milli-Q (10 kDa) overnight (change volume 3 times), and finally obtained as a pale brown powder by freeze-drying (38 mg). 
${ }^{1} \mathrm{H}-\mathrm{NMR}\left(400 \mathrm{MHz}, \mathrm{D}_{2} \mathrm{O}\right): 6.16(\mathrm{~s}, 0.11 \mathrm{H}), 5.92(\mathrm{~s}, 1 \mathrm{H}), 5.52(\mathrm{~s}, 0.16 \mathrm{H}), 5.00(\mathrm{~s}, 0.10 \mathrm{H})$ 4.60-4.06 (m, 9H), 4.03-3.93 (m, 0.35H).

\section{Dynamic light scattering (DLS) and $\zeta$-potential}

DLS and $\zeta$-potential measurements were performed with a Malvern Zetasizer instrument, fitted with a $4 \mathrm{~mW}$ He-Ne laser $(633 \mathrm{~nm})$. A standard operating procedure was used with automatic measuring position and attenuation, with back scattering detection, used for increased sensitivity for smaller particles. Samples were analyzed at $298 \mathrm{~K}$ in glass cuvettes containing $5 \mathrm{mg} \mathrm{mL} \mathrm{m}^{-1}$ of glycogen dissolved in Milli-Q water. $\zeta$-potential measurements were performed in the same manner, though in disposable plastic capillary cuvettes.

\section{Atomic force microscopy (AFM)}

AFM measurements were performed on an Asylum Research Cypher S instrument, and on a JPK NanoWizard II BioAFM instrument, with Bruker RTESPA-300 cantilevers in tapping mode. The BLG and GG were deposited on freshly cleaved mica and clean silica glass, for measurements with the Asylum and JPK instruments, respectively, and dried under nitrogen at a concentration of $0.01 \mathrm{mg} \mathrm{mL} \mathrm{m}^{-1}$.

\section{Optical lightmode waveguide spectroscopy (OWLS)}

OWLS measurements were performed with an OWLS 210 instrument (MicroVacuum, Budapest, Hungary), programmed with Biosense 2.6 software. Measurements were performed on silica coated sensor chips (cleaned with Piranha solution), immersed in degassed and filtered $(0.22 \mu \mathrm{m})$ PNA buffer $(10 \mathrm{mM}$ sodium phosphate, $150 \mathrm{mM} \mathrm{NaCl}, 0.5 \mathrm{mM} \mathrm{CaCl} 2$, $0.5 \mathrm{mM} \mathrm{MgCl} 2$, at $\mathrm{pH} 7.4$ ), under a flow rate of $20 \mu \mathrm{L} \mathrm{min}^{-1}$, which was reduced to $5 \mu \mathrm{L}$

$\min ^{-1}$ upon change in signal from adsorption, at a temperature of $23^{\circ} \mathrm{C}$. Before each sample addition the system was allowed to equilibrate until the change in signal (both $n_{T M}$ and $n_{T E}$ ) 
with time was less than $10^{-8}$. The concentration of all injected samples was $1 \mathrm{mg} \mathrm{mL}^{-1}$, unless stated otherwise.

\section{Quartz crystal microbalance with dissipation (QCM-D)}

QCM-D measurements were performed with a QSense E4 instrument equipped with a peristaltic pump. Gold sensor chips were cleaned with piranha solution prior to measurements. All harmonics were tested in dry and wet state to ensure sensor chip condition. The system was allowed to equilibrate in PNA buffer at $23{ }^{\circ} \mathrm{C}$ for $60 \mathrm{~min}$, then PEI was flushed through (1 $\left.\mathrm{mg} \mathrm{mL}^{-1}\right)$, followed by PNA $\left(1 \mathrm{mg} \mathrm{mL}^{-1}\right)$, and then GG $\left(1 \mathrm{mg} \mathrm{mL}^{-1}\right)$.

\section{FITC labeling of glycogen}

Both glycogen types, GG (20 mg) and BLG (20 mg), were dissolved separately in Milli-Q water. To this $20 \mu \mathrm{L}$ of FITC solution $\left(30 \mathrm{mg} \mathrm{mL}^{-1}\right.$ in DMSO) was added and left mixing for 16 h. Excess FITC was removed by purification on an Ilustra Nap-10 Sephadex column (GE Healthcare Life Sciences) and subsequently freeze-dried.

\section{MTT assay}

PC3 cells were plated on 96-well plates (Costar 3596, Corning, MA, USA) with a seeding density of $5.0 \times 10^{3}$ cells per well in $100 \mu \mathrm{L}$ of DMEM supplemented with $10 \%$ FBS and incubated at $37{ }^{\circ} \mathrm{C}$ and $5 \% \mathrm{CO}_{2}$ overnight. GG and BLG particles were added to culture media at various concentrations and cultured for 24 and $48 \mathrm{~h}$. Cell viability was assessed by standard MTT assay, measuring well absorbance at $554 \mathrm{~nm}$ and $670 \mathrm{~nm}$ as reference by Infinite M200 microplate reader (Tecan, Switzerland). 


\section{Flow cytometry}

PC3 cells were plated on a 12-well plate (Costar 3516, Coring, MA, USA) with seeding density of $1.0 \times 10^{5}$ cells per well in $1 \mathrm{~mL}$ of DMEM media supplemented with $10 \%$ FBS and incubated at $37{ }^{\circ} \mathrm{C}$ saturated with $5 \% \mathrm{CO}_{2}$. After $24 \mathrm{~h}$, cells were placed on ice, washed once with cold DPBS and covered with 1\% BSA in PBS. Bovine liver glycogen (BLG) and galacto-glycogen $(\mathrm{GG})$ were labeled with FITC, and added to a final concentration of 0.2 $\mathrm{mg} \mathrm{mL}^{-1}$, and incubated on ice for $1 \mathrm{~h}$. Cells were washed twice with $1 \%$ BSA in PBS, scratched from the plate surface using a cell scraper. Fluorescence intensity was analyzed using a Partec CyFlow flow cytometer, collecting 10000 cells per treatment.

\section{Confocal microscopy}

PC3 cells were seeded at 30000 cells/well in a Labtek 8-well chamber and incubated for 24 h. The chamber was moved on ice and washed once with DPBS. Solutions of FITC-labeled BLG and GG (see above) at $0.4 \mathrm{mg} \mathrm{mL}^{-1}$ (in 1\% BSA in PBS) were added to the cells and incubated for a further $30 \mathrm{~min}$ on ice. Samples were washed twice with $1 \%$ BSA in PBS and confocal microscopy images were recorded on live cells using a Nikon A1R Confocal Laser Microscope with a $60 \times$ objective. Green emission of the FITC-labeled glycogen was collected by exciting at $\lambda=488 \mathrm{~nm}$ and using the relevant emission filter.

\section{Cell aggregation assay}

PC3 cell suspensions (50 000 cells in $1 \mathrm{~mL}$ of DMEM with 10\% FBS) were treated with BLG and GG, respectively, at a final concentration of $0.4 \mathrm{mg} \mathrm{mL}^{-1}$, and incubated in a 12-well plate at $37{ }^{\circ} \mathrm{C}$ and $5 \% \mathrm{CO}_{2}$ overnight. Images of cells were taken with an inverted microscope with a $10 \times$ objective (Olympus IX71). 


\section{Glycogen degradability}

The degradability of glycogen particles by $\alpha$-amylase was determined using phenol-sulphuric acid assay. 'Simply, $200 \mu \mathrm{L}$ of a $0.25 \mathrm{mg} \mathrm{mL}^{-1}$ solution of BLG and GG, respectively, were treated with an $\alpha$-amylase solution $\left(0.5 \mathrm{U} \mathrm{mg}^{-1}\right)$ in PBS buffer $(120 \mathrm{mM}, \mathrm{pH} 7.4)$ for 3 hours, followed by separation of the particles from enzyme and undigested glycogen by spin columns with a pore size of $30 \mathrm{kDa}$. Of the supernatant, $50 \mu \mathrm{L}$ was transferred into a fresh tube and subsequently treated with $150 \mu \mathrm{L}$ of concentrated sulphuric acid and 30 $\mu \mathrm{L}$ of phenol solution (5\% in water) and incubated for 5 min at $90{ }^{\circ} \mathrm{C}$. Then $100 \mu \mathrm{L}$ was transferred into a 96 well plate (Costar 3596, Corning, MA, USA), and absorbance measured (490 nm) with an Infinite M200 microplate reader (Tecan, Switzerland) in quadruplicates. To determine the total amount of glucose in BLG and GG, PBS buffer was replaced by TFA, and particles treated with $200 \mu \mathrm{L}$ of $0.2 \mathrm{M}$ TFA for $3 \mathrm{~h}$ at $80^{\circ} \mathrm{C}$. Then the procedure described above was followed.

\section{Results and Discussion}

The concept that nanoparticle multivalency can be used to control Gal-1 mediated cellular activities has previously been studied with lactose-functionalized dendrimer particles, and with galactan-functionalised nanoparticles. ${ }^{?}$ The nature of the lactose/galactan to dendrimer/nanoparticle linkage likely impacts the ability of the galactose ligands to effectively bind to their receptors, or the ability of the linker to avoid unfavorable stereoelectronic interactions outside of the binding site. ${ }^{?}$ To avoid unfavorable interactions outside of Gal-1's binding pocket, we incorporate lactose moieties on glycogen through a short triazole linkage between glucose residues in lactose and on glycogen, achieved through copper(I)-catalyzed alkyne-azide cycloaddition (CuAAC) (??).

Briefly, alkyne groups were first incorporated onto the C6 position of chain ends. These were subsequently reacted with 1-O-(2-azidoethyl)-hepta- $O$-acetyl-lactoside to yield a tria- 
zole linkage between the glycogen chain and an acetylated lactose. This product was then deprotected to yield lactosylated-glycogen, which contains terminal $\beta$-galactoside moieties, which from hereon is termed "galacto-glycogen" (GG). The lactose functionality is designed for targeted interaction with $\beta$-galactoside binding proteins, such as Gal-1. By utilizing glycogen as the anchoring nanoparticle a self-similar structure is achieved between glucose

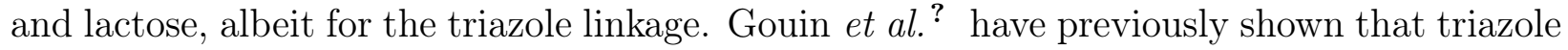
linkages between multivalent lactosides does not affect the binding with $\beta$-galactoside-specific lectins.

The degree of functionalization of BLG with lactose moieties was characterized from the ${ }^{1} \mathrm{H}$ NMR spectrum (see Figure S2). The signal corresponding to the new alkyne proton has an integral of 0.05 compared to the $\mathrm{H} 1$ proton of BLG, therefore showing that BLG has $5 \%$ of glucose monomers modified with alkyne moieties. This alkyne modification occurs on either the 2 or 6 position of the non-reducing end of glucose. Separate reactions were performed using different amounts of propargyl bromide with the aim of varying the modification degree, however, $\mathrm{a} \approx 5 \%$ degree of glucose modification with alkyne moieties was consistently found by NMR (data not shown), suggesting this is a functionalization limit given the solvent system chosen. The following click reactions are performed in excess of 1 - $O$-(2-azidoethyl)hepta- $O$-acetyl-lactoside, leading to a complete conversion of alkyne groups to triazole linked lactose, as confirmed by ${ }^{1} \mathrm{H}$ NMR (note disappearance of alkyne peak in Figures $\mathrm{S} 2$ and S3). The product GG therefore has $5 \%$ of glucose molecules modified with the triazole linked lactose. This corresponds to about 110 molecules of lactose attached to a single glycogen particle, based on a BLG molecular weight of $360 \mathrm{kDa}$ (as determined by static light scattering, see Figure S6). If the click reaction was performed quantitatively, rather than in excess, alkyne moieties may remain, which can then be exploited to further functionalize GG with other sugars and/or drugs.

Bertoldo et al. ${ }^{?}$ have shown that modification of glycogen nanoparticles occurs predominately on the solvent-exposed surface, especially when reactions are performed in organic 
solvents. This is thought to occur due to the slow swelling kinetics of glycogen in these solvents. Given the reaction conditions for forming glycogen alkyne, the first step of glycogen functionalization (see ??), was performed in a mixed DMSO/DMF system, it is also expected that the final GG nanoparticles predominately have lactose ligands on the surface, which should lead to enhanced interaction with lectin proteins.

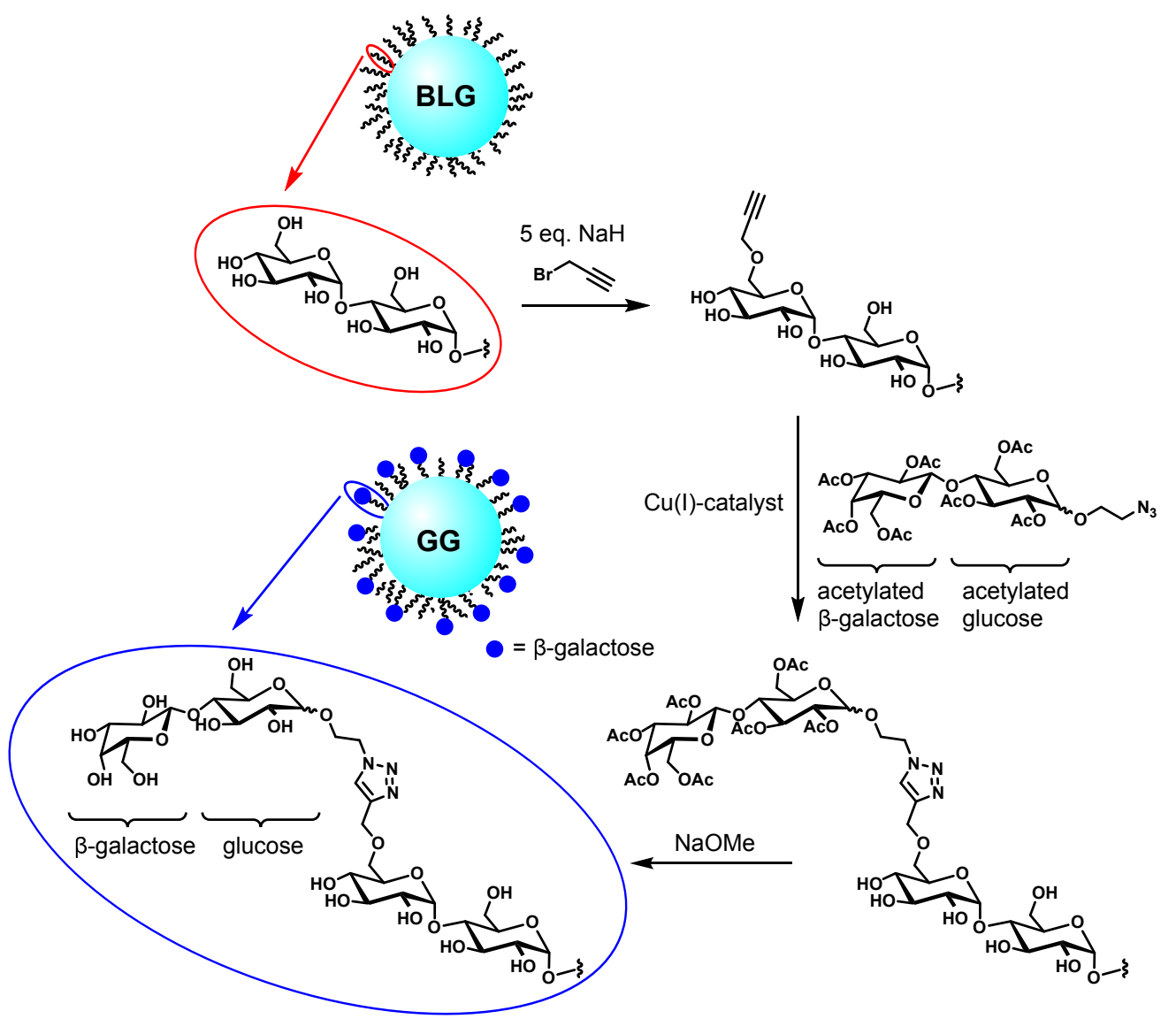

Figure 1. Reaction schematic for the modification of bovine liver glycogen (BLG) to generate galacto-glycogen (GG).

The isolation of GG by freeze-drying can result in the formation of minor aggregate species. This may result from glycogen chains of separate particles condensing together, producing supermolecular glycogen. Intense probe-sonication can only marginally degrade these species (data not shown). It has previously been shown that glycogen can form various nanostructures during the freeze-drying process, with a morphology that is dependent on

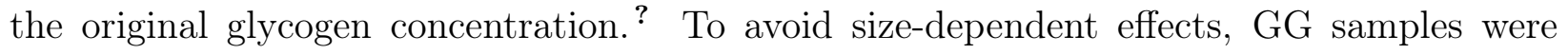


filtered before using further $(0.22 \mu \mathrm{m}$ filter $)$. The subsequent DLS intensity distributions (see ??A) show that GG is marginally larger than BLG, which is consistent with there being few large aggregate species, but on a population average being monodisperse (note the GG number distribution converged near the BLG distribution). Both GG and BLG have a intensity-averaged $d_{H}^{D L S}$ of about $20 \pm 8 \mathrm{~nm}$ (for the smaller distribution in the GG bimodal distribution). The $\zeta$-potential between the two samples was about the same at $-10 \mathrm{mV}$, consistent with a small amount of phosphate present on the particles surfaces, ${ }^{?}$ resulting from the action of phosphorylating enzymes in vivo.? This indicates that the chemical modification does not affect the colloidal stability of the GG nanoparticles. For a separate measure of particle size and dispersity, dry-state AFM was performed on GG deposited on silica glass and on freshly cleaved mica (??C and insert, respectively). The AFM shows that GG particles are monodisperse and roughly spherical in shape. The line profile of these data (??D) show the particles have a small dry-height of the order of $3 \mathrm{~nm}$ and below. This is likely a consequence of dehydration, or a result of the particles being deformed by the AFM cantilever. The diameters (width) of the GG nanoparticles is $\left\langle d_{A F M}^{G G}\right\rangle=46 \pm 12 \mathrm{~nm}$, whereas that of BLG nanoparticles is $\left\langle d_{A F M}^{B L G}\right\rangle=34 \pm 6 \mathrm{~nm}$ (see Figure S7).

The principal aim in this article is to evaluate the effectiveness of the lactose functionalization of glycogen for targeted interactions with $\beta$-galactoside-specific lectins. The ultimate goal is to test the binding of GG to Gal-1, which is an overexpressed $\beta$-galactoside binding protein in prostate cancer (PC3) cells. We first characterize the physical binding characteristics of GG to a layer of another $\beta$-galactoside-specific protein, peanut agglutinin (PNA), which has previously been used to characterize glycan-lectin interactions with excellent discrimination between target and non-target sugar moieties. ${ }^{\text {' }}$ By first checking the adsorption and binding characteristics of GG to PNA, we can assume a targeted interaction of GG with PC3 cells through the Gal-1 carbohydrate binding domain.

The ex situ OWLS technique was used to provide quantitative data on adsorbed mass for a system comprising a silica-coated sensor chip, poly(ethyleneimine) (PEI), PNA, and then 

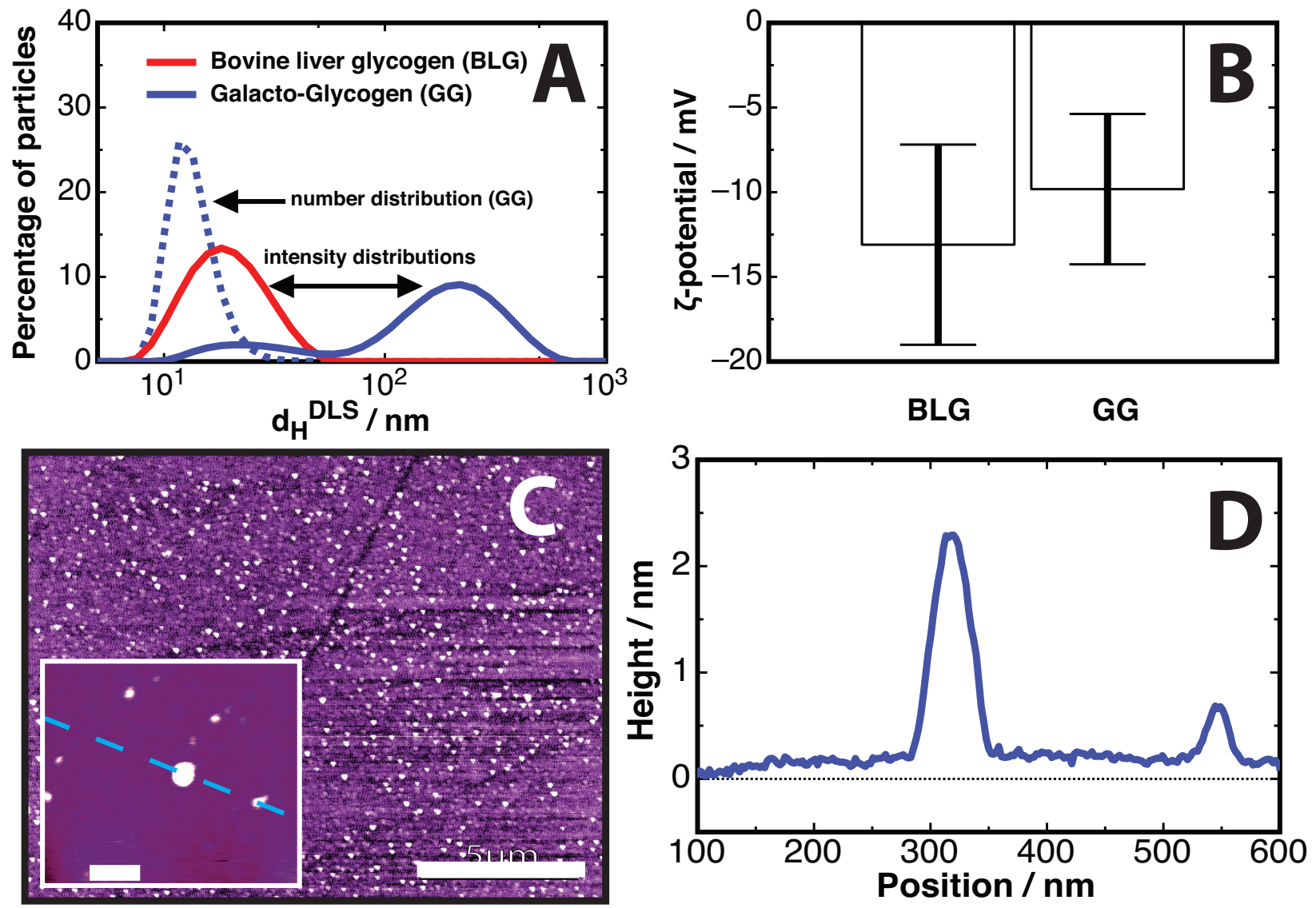

Figure 2. DLS intensity distributions (solid lines) of BLG (red) and GG (blue), and number distribution of GG (blue dotted line) (A), $\zeta$-potentials of BLG and GG (B), AFM image of GG on glass (C) and mica (insert), scale bars $5 \mu \mathrm{m}$ and $100 \mathrm{~nm}$, respectively, and the accompanying line profile (D). 
GG. The basic principal of the method consists of measuring the mode spectrum of an optical waveguide, the surface of which is exposed to the solution of polymer/biomolecules, ${ }^{?}$ and is very sensitive to changes in the refractive index of this layer. Measurements were performed on sensor chips that were allowed to equilibrate in PNA buffer until $\partial M / \partial t<10^{-8}$, where $M$ is the adsorbed mass as a function of time. To this, PEI in PNA buffer $\left(1 \mathrm{mg} \mathrm{mL}^{-1}\right)$ was injected at a flow rate of $20 \mu \mathrm{L} \mathrm{min}{ }^{-1}$. Once a change in signal was observed the flow rate was reduced to $5 \mu \mathrm{L} \mathrm{min}{ }^{-1}$. The adsorption of PEI to the silica substrate is electrostatic in origin. ? Upon signal stabilization, PNA in buffer $\left(1 \mathrm{mg} \mathrm{mL}^{-1}\right)$ was injected and the process repeated, where the binding of PNA to PEI is also electrostatic in origin. Once the system was equilibrated, GG in buffer $\left(1 \mathrm{mg} \mathrm{mL}^{-1}\right)$ was injected. As seen in ??A, an increase in adsorbed mass is seen for GG on PNA, indicating successful binding of GG to PNA's active site. A noticeable difference in the adsorption curve between GG-PNA and the electrostatic PNA-PEI interaction is evident. 'Given that GG has a negative $\zeta$-potential, like PNA, the interaction between GG and PNA is not electrostatic in origin, but results from the targeted interaction between the lactose moieties and the active site of the PNA protein.

These measurements were repeated with different GG samples, as shown in ??B, where all systems showed a similar plateau, and adsorption rate kinetics. Furthermore, when the experiment is repeated with BLG, there is very little change in adsorbed mass (see insert in ??B). This minor change in signal may be due to a weak electrostatic interaction between residual exposed PEI chains and BLG. However, this interaction is minor in comparison to GG, supporting the ligand-receptor-mediated interaction between a monolayer of PNA and the GG particles, as opposed to bare BLG.

These results were further confirmed by QCM-D, which showed complementary results to the OWLS measurements (see Figure S8). An alternative solution-based binding between PNA and GG was analyzed by real-time DLS (??C), whereby size measurements were performed on GG in solution, and then continued for a period of 55 minutes after an excess of PNA was injected. It was found that particles start aggregating immediately, and continue 

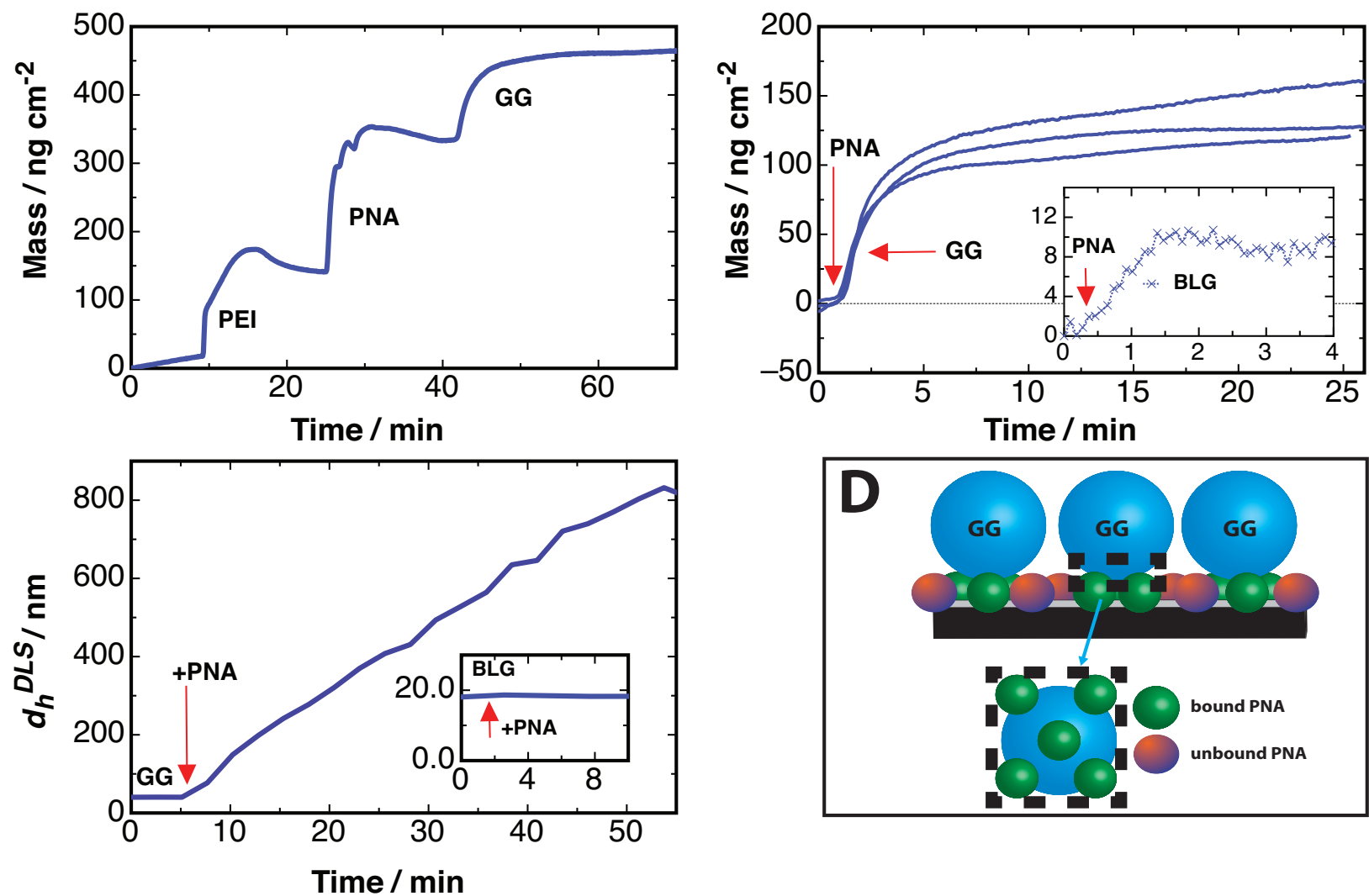

Figure 3. OWLS measurements of the adsorbed mass on a system of silica/ PEI/ PNA/ GG (A), and for triplicate measurements of the GG adsorbed mass (B) and for the control BLG (insert), DLS measurements of GG aggregating after addition of PNA into solution (C), and the control BLG system (insert), and a schematic of the adsorbed GG nanoparticles on the PNA surface (D) 
up until the point of precipitation, at which point the auto-correlation function fails to fit a size distribution. As the GG-PNA aggregate grows in size the solution changes from transparent to a milky appearance (see Figure S9), before precipitate appears. On the other hand, when PNA was added to BLG particles, no change in particle size distributions occurred, nor change in transparency. These tests show that lactose moieties have been successfully added onto glycogen particles in such a way that it may interact with the $\beta$-galactoside-specific lectin PNA.

The adsorbed mass measurements (??A) allow information to be obtained on the number of PNA proteins that are bound to one side of a GG particle. PNA exists as a tetramer with four binding sites, ${ }^{?}$ however, the monolayer likely has only one or two of these binding sites exposed to the environment above. The mass per unit area of PNA, $\Delta M_{P N A}$, of $190 \mathrm{ng}$ $\mathrm{cm}^{-2}$ which corresponds to $1.73 \mathrm{pmol} \mathrm{cm}^{-2}$, assuming a weight-averaged molecular weight of PNA, $M_{W}^{P N A}$, to be 110000 Da. ? The "bound" GG has a mass per unit area, $\Delta M_{G G}$, of about $130 \mathrm{ng} \mathrm{cm}{ }^{-2}$, corresponding to $0.36 \mathrm{pmol} \mathrm{cm}^{-2}$, assuming $M_{W}^{G G}$ of $360000 \mathrm{Da}$ (see Figure S6). Therefore the fraction of bound GG to the PNA monolayer may be expressed as

$$
\phi=\frac{\Delta M_{G G} M_{W}^{P N A}}{\Delta M_{P N A} M_{W}^{G G}},
$$

which evaluates to $\phi \approx 0.20$, indicating that for each GG particle, there are 5 PNA tetramer proteins bound. This binding is likely a one-step event as the GG solution washes over the PNA activated surface. Note that this fraction of bound proteins is only on one surface of the GG particles, as the method is based on a "layering" approach, as opposed to a 3dimensional saturation of GG with PNA in solution. This is schematically shown in ??D. The structure of GG with respect to the density of lactose ligands is therefore well-suited to interact with multiple binding sites on different PNA proteins. This multivalent property of GG may enhance the interaction with $\beta$-galactoside-specific extracellular lectins, whereby the likelihood of the nanoparticle coming into contact with lectin receptors is increased while the nanoparticle traverses the extracellular space. Even though the distribution of lectins 
on human cells are most likely not as densely presented as a purely PNA coated surface, the GG multivalency may ultimately lead to enhanced cellular internalization, aggregate cells by cross-linking $\beta$-galactoside-specific lectins on alternative cells, and/or inhibit cell proliferation mediated through $\beta$-galactoside-specific lectins such as Gal-1, for example.

The observed interaction of GG with multiple PNA proteins occurs at a degree of functionalization of $5 \%$ of glucose units in glycogen converted to glucose-lactose moieties, which we assume primarily occurs at the surface. ' These binding properties may therefore be tuned by varying the concentration of lactose moieties on the GG nanoparticle. The change in binding kinetics and cross-linking capacity of differently substituted GG particles with galactose-specific lectins is the subject of a future study.

To establish the affinity of GG for PNA, the change in adsorbed mass of GG as a function of the concentration of GG that interacts with a surface saturated with PNA was evaluated. ??A depicts the dependence of mass change on the concentration of GG flushed through the system. This approach has the assumption that GG may equilibrate with the PNA surface in such a way so that further GG-PNA interactions are not inhibited by the distribution of bound GG particles. The adsorption equilibrium may be represented as

$$
\begin{array}{r}
\mathrm{GG}_{\mathrm{x}}+\mathrm{PNA}_{\mathrm{y}} \rightleftharpoons\left(\mathrm{GG}_{\mathrm{x}} / \mathrm{PNA}_{\mathrm{x} / \phi}\right)+\mathrm{PNA}_{\mathrm{y}-\mathrm{x} / \phi}, \\
\left(\mathrm{GG}_{\mathrm{x}} / \mathrm{PNA}_{\mathrm{x} / \phi}\right)+\mathrm{PNA}_{\mathrm{y}-\mathrm{x} / \phi}+\mathrm{GG}_{\mathrm{z}} \rightleftharpoons\left(\mathrm{GG}_{\mathrm{x}+\mathrm{z}} / \mathrm{PNA}_{(\mathrm{x}+\mathrm{z}) / \phi}\right)+\mathrm{PNA}_{\mathrm{y}-(\mathrm{x}+\mathrm{z}) / \phi},
\end{array}
$$

where the subscripts $x, y$, and $z$ indicate concentration coefficients, and $\phi$ the fraction of GG to PNA (??). This process is repeated until the $\Delta M$ saturates (i.e. $\mathrm{PNA}_{y / \phi-(x+z) / \phi}=$ $\left.\mathrm{GG}_{y-(x+z)}\right)$, where a typical saturation plateau is seen (??B). Each injection step is allowed to equilibrate until $\partial \Delta M / \partial t<10^{-8}$, before the next concentration series is injected. Assuming a homogenous distribution of equal receptor sites on the PNA protein layer, and the same for lactose-sites on the GG, the Langmuir adsorption isotherm is a useful model to describe 
the affinity of GG for PNA, where the model may be fitted to the data in ??B with

$$
\Delta M=\Delta M_{\max } \frac{[G G] k_{A}}{1+[G G] k_{A}},
$$

where $\Delta M_{\max }$ is the maximum change in mass (i.e. all protein saturated with $\mathrm{GG}$ ), $[G G]$ is the concentration of GG, and $k_{A}$ is the affinity of GG for PNA. Fitting ?? to the change in adsorbed mass as a function of GG in ??B, we find $\Delta M=91.5 \mathrm{ng} \mathrm{cm} \mathrm{cm}^{-2}$, and the affinity of GG to PNA, $k_{A}$, to be $3.41 \times 10^{5} \pm 1.32 \times 10^{5} M^{-1}$. This affinity is only marginally less than that for BLG with a glucose-specific lectin, Concanavalin-A (Con-A), which has a $k_{A}$ of $6.91 \times 10^{5} \mathrm{M}^{-1}$, as obtained by the same experimental protocol (see Figure S10).

The saturated adsorbed mass of GG on PNA in ?? is less than that for ??A, which may be a consequence of the sequential increasing of concentration of GG, whereby not all binding sites may be accessible to subsequent injections of GG. Our methods therefore have the approximation that the equilibrium concentration of GG is about equal to the total concentration of GG, which is valid only when the GG dissociation constant, $k_{D}$, is higher than the PNA concentration. The measured affinity constant of GG for PNA is in good agreement with previous studies by Janshoff et al., ${ }^{\text {? }}$ who found a $k_{A}$ of PNA for $\beta$-galactoside-functionalized surfaces of $8.3 \times 10^{5} \mathrm{M}^{-1}$.
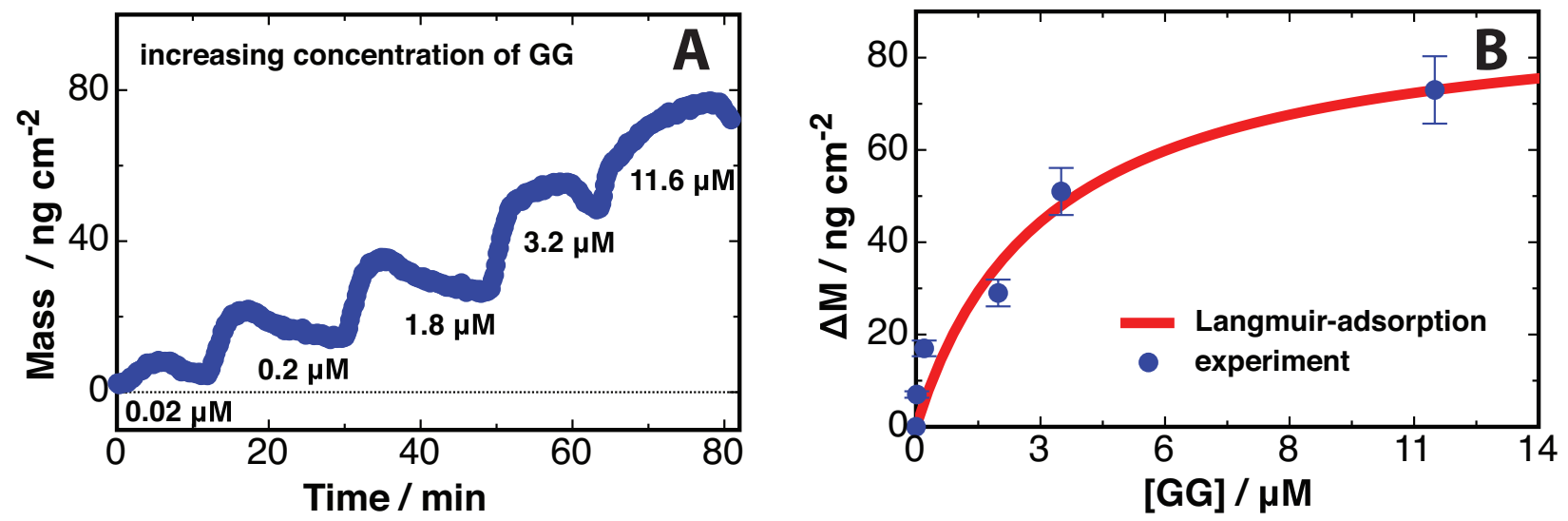

Figure 4. OWLS measurements for the affinity of GG for PNA, whereby the change in adsorbed mass is studied as a function of $[\mathrm{GG}](\mathrm{A})$, and the results fitted against a Langmuiradsorption model (B). 
This strong affinity of GG nanoparticles for PNA indicates that GG may be a competitive ligand for $\beta$-galactoside-specific lectins. The strength of the GG-PNA interaction is tested by first incubating GG to PNA for ligand-receptor binding, then after the system is equilibrated lactose is injected and allowed to interact with the GG-PNA complexes (see ??A). It is found that even at concentrations of lactose spanning $10 \mathrm{mM}$ up to $80 \mathrm{mM}$, the GG particles cannot be displaced from the PNA. A change in signal is observed as concentration of lactose meets the GG-PNA complex, which is the result of the change in refractive index in the covering solution above the GG-PNA complexes. This is confirmed as once the lactose solutions wash past the GG-PNA complexes the signal returns to normal. Since the signal returns to the original position for just GG-PNA complexes, this experiment demonstrates that the interaction between GG-PNA is strong enough to overcome competitive binding by small $\beta$-galactosides.
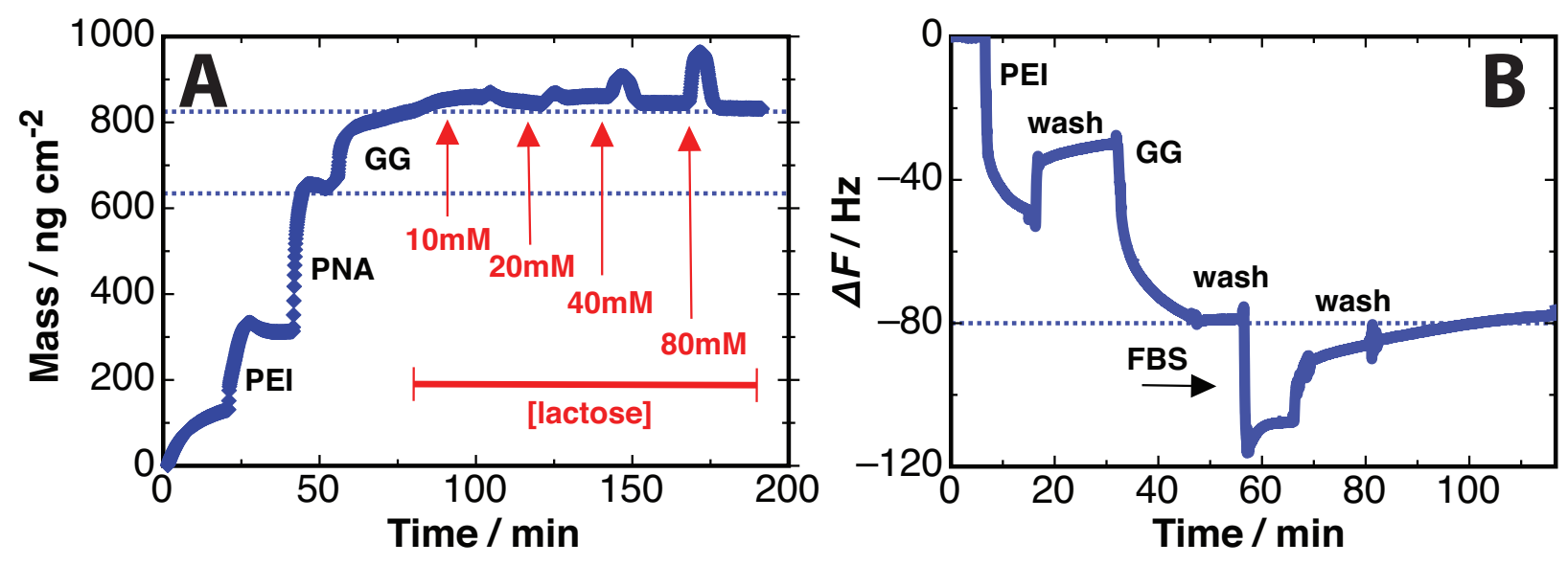

Figure 5. OWLS measurements for the possible displacement of the GG-PNA complex by lactose (A), and QCM-D measurement for the fouling of GG with serum proteins (B), whereby GG is first adsorbed on a bed of PEI, then 10\% FBS solution in PBS buffer is injected and allowed to interact before washing.

Ideally the GG particles should exhibit low fouling properties in the presence of serum proteins, which would promote long circulation lifetimes in vivo. To check this property QCM-D was performed on a system of GG adsorbed on PEI, which was adsorbed on gold sensor chips, all in PBS buffer. To this system a solution of $10 \%$ fetal bovine serum (FBS) was injected and allowed to interact with the GG layer (see ??B). As seen in ??B at 55 
min, the FBS settles onto the GG particles but then washes straight off under gentle flow, demonstrating the GG-serum interaction is weak. This shows that the GG particles are low fouling and may therefore have long circulation lifetimes in the in vivo serum.

Gal-1 is a $\beta$-galactoside-specific lectin that is overexpressed both within and on PC3 cells. Gal-1 plays an important role in cell adhesion to the extracellular matrix, cell migration, and cell-cell communication. Firstly, the toxicity of the GG particles to PC3 cells needs to be evaluated to prove that GG can be used as an imaging agent and/or drug delivery vehicle. A standard MTT assay was performed whereby the PC3 cells were incubated in different concentrations of GG over a period of 24 and $48 \mathrm{~h}$ (see ??A). The assay revealed that the GG particles are not toxic and retain this property compared to native BGL (see Figure S11), where over both periods of time and across all concentrations of GG, the viability of cells in comparison to untreated cells was almost $100 \%$ in all cases.

The degradability of GG and BLG was evaluated by an $\alpha$-amylase degradation assay. It was found that both BLG and GG are both degradable to a similar extent of about $50 \%$ and $40 \%$, respectively (see ??B), after about $3 \mathrm{~h}$ of incubation with $\alpha$-amylase. This shows that the GG nanoparticles are both biocompatible and biodegradable, highlighting their potential for use in therapeutic applications.

The targeting ability of GG to PC3 cells was evaluated by flow cytometry and confocal microscopy. Cells were incubated for $24 \mathrm{~h}$ with BLG and GG nanoparticles, respectively, on ice using a $1 \%$ BSA solution in PBS in order to slow down cellular internalization pathways and inhibit nonspecific interactions with the cell membranes, meaning only particles that have a high affinity to extracellular lectin proteins should bind to the cells surface. The flow cytometry data (??) indicate markedly increased fluorescence intensity in cells treated with GG, whereas fluorescence of cells treated with BLG remained similar to the untreated control. These data demonstrate a high affinity of GG to PC3 cells in comparison to BLG particles, which do not specifically associate with PC3 cells. On the basis of previously discussed ex vivo results, these results suggest specific interaction of the lactose ligands on 

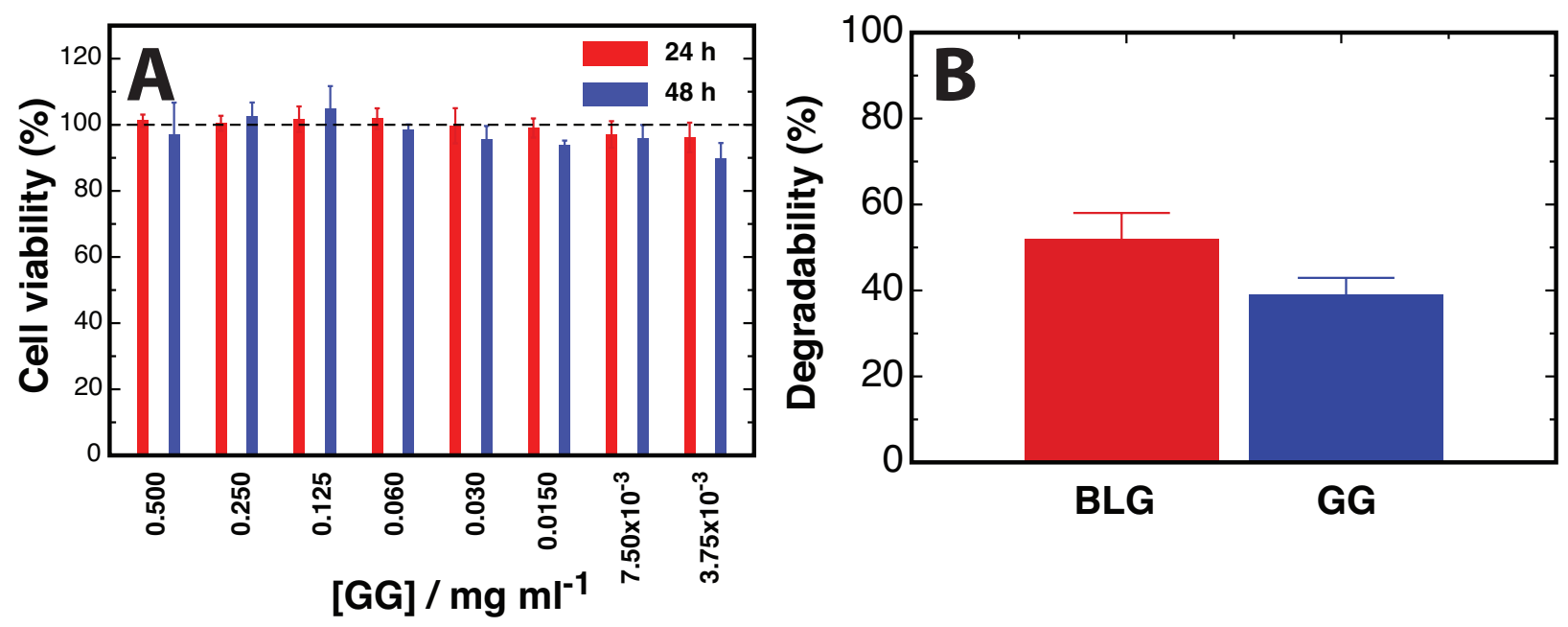

Figure 6. MTT assay of cell viability of PC3 cells incubated with GG in relation to untreated cells over two periods of time (24 and $48 \mathrm{~h}$ ) (A), and an $\alpha$-amylase degradation assay of BLG and GG nanoparticles over a period of $3 \mathrm{~h}$ to determine the degradability of each particle type (B).

GG particles with extracellular lectins on PC3 cells, particularly with Gal-1.

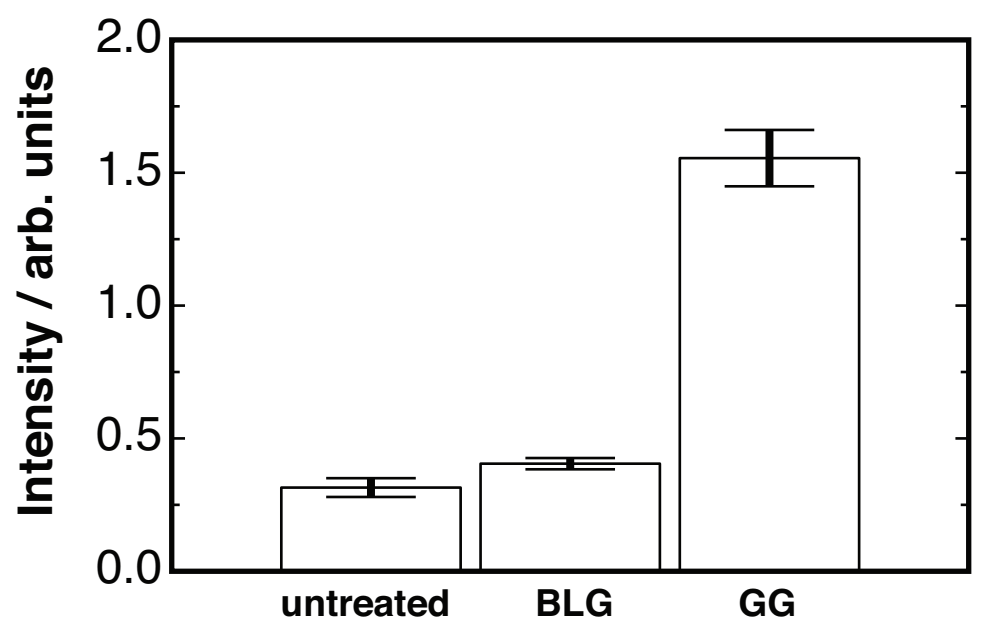

Figure 7. Flow cytometry fluorescence intensity of untreated PC3 cells, and PC3 cells incubated with BLG and with GG for $24 \mathrm{~h}$, as measured by flow cytometry. Error bars indicate the standard deviation.

These results were subsequently confirmed by confocal microscopy, where cells treated in the same way as for flow cytometry were imaged using FITC and bright field filters. Confocal and bright field microscopy images of untreated (??A and D) and BLG treated (??B and E) PC3 cells show no observable fluorescence and a weak negligible fluorescence, 
respectively. Conversely, a strong fluorescence signal was observed on PC3 cells incubated with GG (??C and F), indicating the specific binding of GG to the membrane, which we suggest is to extracellular Gal-1 proteins.
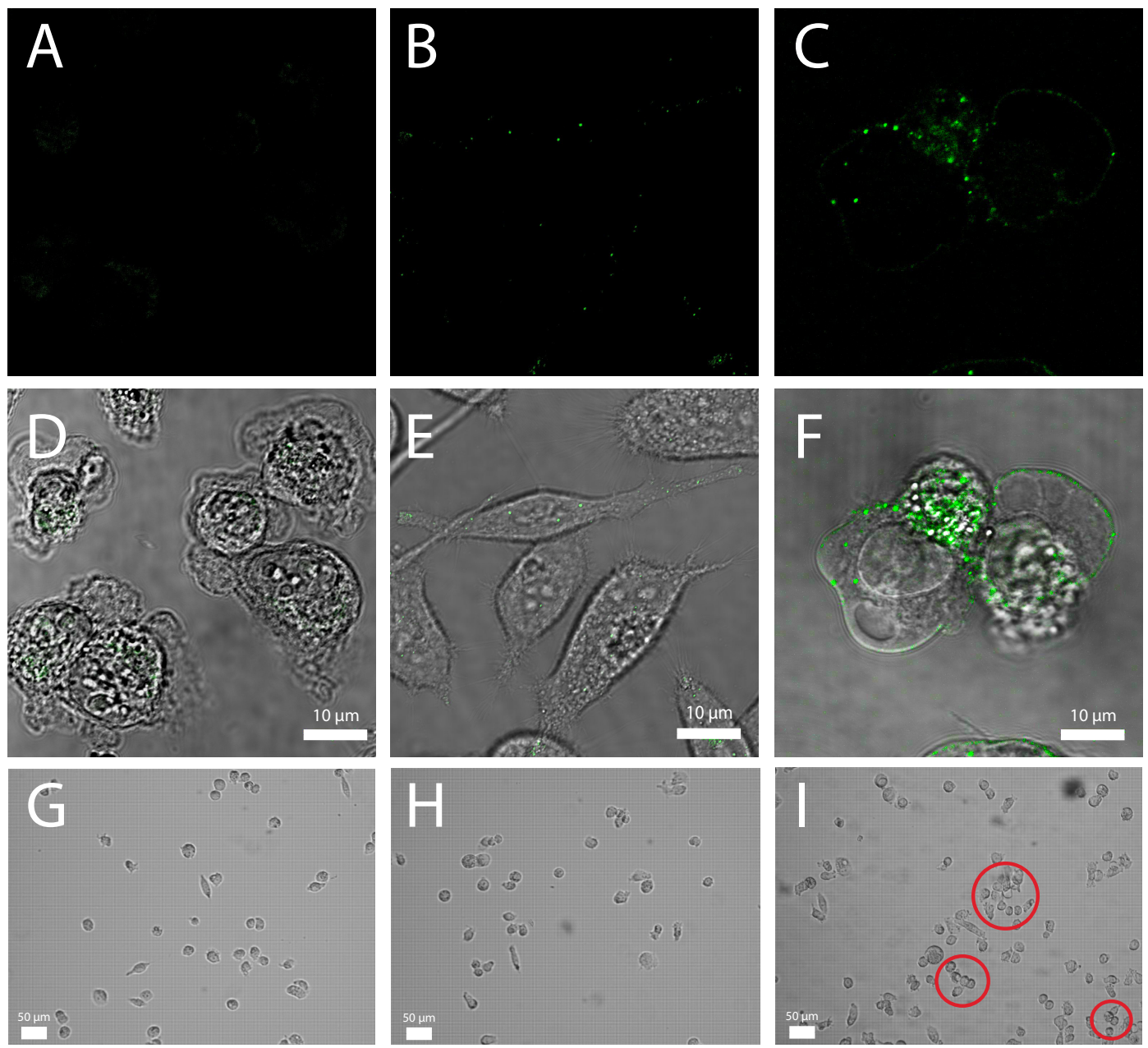

Figure 8. Confocal microscopy of FITC filtered and bright field composite images of a control $(\mathrm{A}, \mathrm{D})$, and of BLG $(\mathrm{B}, \mathrm{E})$ and $\mathrm{GG}(\mathrm{C}, \mathrm{F})$ incubated with PC3 cells for $24 \mathrm{~h}$. Scale bars are $10 \mu \mathrm{m}$ in these images. Confocal microscopy of untreated PC3 cells $(\mathrm{G})$, treated with BLG (H), and with GG (I), both at a concentration of $0.4 \mathrm{mg} \mathrm{mL}^{-1}$ for $12 \mathrm{~h}$. Note the circles in $\mathrm{C}$ highlight regions of inter-cell contact, indicating aggregation. Scale bars are 50 $\mu \mathrm{m}$ in these images.

A cell aggregation assay was performed to investigate the interactions between GG and multiple target proteins across different cells. Cell suspensions were plated together with BLG (??H), and GG (??I), along with an untreated control (??G). Cells treated with GG showed clear aggregation (see regions inside red circles), whereas singular cells are seen for 
the case of BLG and the untreated control. This result is in agreement with the ex situ studies shown in ??C, where instead of GG-induced PNA aggregation, here we observe that GG that is able to seed the aggregation of PC3 cells. The GG-induced aggregation of PC3 cells is likely due to multiple GG-lectin interactions taking place between separate cells, which we suggest is to extracellular Gal-1 proteins. This aggregation stems from the multivalent nature of GG. In addition, the PC3 aggregation study confirms the observation in ??A, where it was estimated that one GG particle can bind up to 5 PNA proteins on one face, demonstrating a competitive multivalency.

Taken together, this work demonstrates how glycogen can be functionalized with a motif allowing for strong interaction with lectins, and ultimately the targeted interaction with prostate cancer cells. This targeted interaction between GG and prostate cancer cells may now be exploited in biomedical research, for instance for imaging cancer cells overexpressing Gal-1, to inhibit the Gal-1 mediated proliferation of cancer cells, or for targeted anticancer drug delivery. Our methods for functionalization are not limited to lactose motifs, though that is the significant motif for the studied interactions herein. Furthermore, the GG nanoparticles may be functionalized with other moieties in addition to lactose, by using other functional azides for further "click" reactions. Such addition of a diverse range of targeting moieties may allow for a greater synergistic uptake by cancer tissue. Our work highlights how a simple biosourced polysaccharide, that is both highly biocompatible and biodegradable, may be used as a starting material to engineer particles for targeted interaction with prostate cancer cells. The interaction of these GG nanoparticles in vivo is the subject of a future study. 


\section{Conclusions}

In summary, we have synthesized GG nanoparticles as a functional material for multivalent binding with lectins and for the targeting of prostate cancer cells, likely through interaction with extracellular galectin-1 (a $\beta$-galactoside binding protein). The GG nanoparticles interact strongly with peanut agglutinin (PNA), another $\beta$-galactoside-specific lectin, as observed ex situ by OWLS, DLS, and QCM measurements. It was found that these GG particles have a strong affinity for PNA of the order of $3.4 \times 10^{5} \mathrm{M}^{-1}$, which cannot be displaced by smaller $\beta$-galactosides, demonstrating a competitiveness of GG for PNA. The GG nanoparticles were tested for association with prostate cancer cell membranes in vitro, where the particles exhibited a high affinity for the membrane, as observed from flow cytometry and confocal microscopy. Furthermore, GG was found to induce aggregation between prostate cancer cells, a consequence of the multivalency of GG. Together, these data show that the biocompatible and biodegradable GG nanoparticles can interact strongly, and competitively, with $\beta$-galactoside-specific proteins, both ex situ and in vitro. Our results highlight a simple strategy for engineering a biosourced polysaccharide with surface moieties that exhibit strong multivalent interactions with lectins, and targeted interaction with prostate cancer cells.

\section{Associated Content}

\section{Supporting Information}

${ }^{1} \mathrm{H}$ NMR spectra of all products, static light scattering of BLG, AFM of BLG, QCM-D of GG/PNA binding, digital photograph of the GG/PNA aggregate solution, QCM-D of BLG binding to Con-A with the application of the Langmuir adsorption model, and an MTT assay of BLG. 


\section{Acknowledgments}

We thank Dr. David Stapleton for helpful discussions and Dr. Christine Browne for AFM assistance. This work was supported by the Australian Research Council (ARC) under the Future Fellowship (F. Cavalieri, FT140100873), and Australian Laureate Fellowship (F. Caruso, FL120100030) schemes. This work was also supported by a University of Melbourne

Establishment Grant. This research was conducted by the ARC Centre of Excellence in Convergent Bio-Nano Science and Technology (project number CE140100036). This work was performed in part at the Materials characterization and Fabrication Platform (MCFP) at the University of Melbourne and the Victorian Node of the Australian National Fabrication Facility (ANFF). 


\section{Graphical TOC Entry}

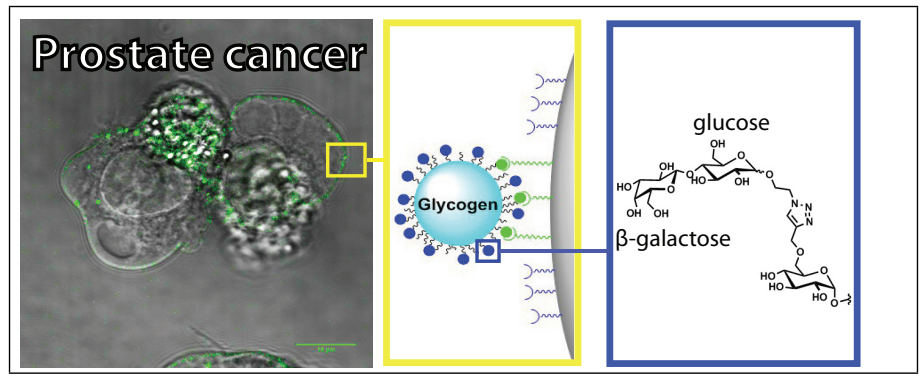

